\title{
APPLICATION OF CMSY TO ESTIMATE BIOLOGICAL REFERENCE POINTS OF BOMBAY DUCK (Harpadon neherus) FROM THE BAY OF BENGAL, BANGLADESH
}

\author{
BARMAN, P. P. ${ }^{1,2}$ - KARIM, E. ${ }^{3}$ - KhATUN, M. H. ${ }^{1}$ - RAHMAN, M. F. ${ }^{1}$ - ALAM, M. S. ${ }^{1,4}-$ \\ LIU, Q. ${ }^{{ }^{*}}$ \\ ${ }^{1}$ College of Fisheries, Ocean University of China, Qingdao 26600, Shandong, P. R. China \\ ${ }^{2}$ Department of Coastal and Marine Fisheries, Sylhet Agricultural University, Sylhet 3100, \\ Bangladesh \\ ${ }^{3}$ Bangladesh Fisheries Research Institute (BFRI), Mymensingh 2201, Bangladesh \\ ${ }^{4}$ Department of Marine Sciences and Fisheries, University of Chittagong, Chittagong 4331, \\ Bangladesh \\ ${ }^{*}$ Corresponding author \\ e-mail:qunliu@ouc.edu.cn
}

(Received 13 $3^{\text {th }}$ May 2020; accepted $14^{\text {th }}$ Aug 2020)

\begin{abstract}
CMSY method was used to calculate Biological Reference Points (BRPs) of Harpadon nehereus using seventeen years (2001-2017) of catch data from the Bay of Bengal (BOB), Bangladesh. CMSY requires only catch and resilience data with quantitative stock status information. Also, a Bayesian statespace implementation of the Schaefer production Model (BSM) was used. The lowest Maximum Sustainable Yield (MSY) was provided by BSM $(60600 \mathrm{t})$ that was smaller than last year's catch $(82767 \mathrm{t}$ in 2017). The fishing mortality $(F)$ was estimated to be 0.22 and 0.23 for CMSY and BSM, respectively. The intrinsic population growth rate $(r)$ was lower according to BSM $(0.37)$ than the CMSY $(0.57)$. Calculated $B / B_{\mathrm{MSY}}$ was 1.13 and $F / F_{\mathrm{MSY}}$ was 1.21 from the BSM model for the last data year. Estimated BRPs directed the overfishing status that may lead the H. nehereus fishery to be unsustainable. Therefore, proper management strategies are required to ensure the sustainability of $H$. nehereus in the BOB, Bangladesh.
\end{abstract}

Keywords: CMSY, BSM, population dynamics, maximum sustainable yield, biomass, exploitation, overfishing, sustainable management

\section{Introduction}

Bangladesh is a Southeast Asian country blessed with the Bay of Bengal (BOB). The $\mathrm{BOB}$ is a part of Indian Ocean and the only maritime fishery resource in Bangladesh. The total area of the BOB is 2172000 square $\mathrm{km}$ whereas Bangladesh occupies 121110 square $\mathrm{km}$ after the maritime border settlement with India and Myanmar (Kumar et al., 2016). This vast area is enriched with 475 fish species but only few of them are commercially harvested as target species. Harpadon nehereus (Hamilton, 1822) commonly known as Bombay duck and locally called "lottia". Bombay duck is one of the most commercially important species constituted above $10 \%$ of the total marine catch over the past decades from the BOB, Bangladesh (DoF, 2018). This is not only well demanded by the national and coastal population of Bangladesh but also has good export value both in fresh and dry condition (Barua et al., 2014; Fernandes et al., 2015; Sarker et al., 2017). However, due to increasing market demand, fishing pressure is also increasing. As a result, BOB fisheries stocks are in crisis including excessive fishing efforts, illegal fishing, and other 
man made causes (Hossain et al., 2015). Scientific research and studies are prerequisite to ensure the sustainable management of this valuable fisheries in the BOB. Some work has done on growth, mortality and length-weight relationships (Mustafa et al., 1998; Amin, 2001; Sarker et al., 2017) but there is no research on the Biological Reference Points (BRPs) of $H$. nehereus from the BOB, Bangladesh.

The widely used and accepted target BRP for fisheries management is Maximum Sustainable Yield (MSY) while other BRPs are also used for fisheries management (Siddeek et al., 2004; Panhwar et al., 2012; Wang and Liu, 2013; Zhang and Chen, 2015; Mohsin et al., 2017; Karim et al., 2018; Zhang et al., 2018; Ji et al., 2019). Several computer tools and packages such as CEDA (Kirkwood et al., 2003), ASPIC (Prager, 2005), Catch-MSY (Martell and Froese, 2013), CMSY (Froese et al., 2017) are used to calculate the MSY and other BRPs by the researchers and fishery managers. Among them, CMSY is one of the most recent method developed by Froese et al. (2017). CMSY is a Monte Carlo Method based model and the most suited methods to calculate the MSY and BRPs of data limited fisheries (Froese et al., 2017). It was reported that CMSY can provide better performances than other methods to estimate the BRPs and convenient for developing and least-developed countries who have a short time data series (MacCall, 2009; Dick and MacCall, 2011; Martell and Froese, 2013; Rosenberg et al., 2014; Ji et al., 2019). The CMSY model needs only catch and resilience data and when catch and catch per unit effort (CPUE) data are available, a Bayesian state-space implementation of the Schaefer production model (BSM) can also be used (Froese et al., 2017). CMSY and BSM can estimates the intrinsic population growth rate $(r)$, carrying capacity or unexploited stock size $(k)$, maximum sustainable yield (MSY) and other fisheries reference points. Additionally, CMSY can display a sensible evaluation of exploitation rate and relative biomass (Froese et al., 2017). This study aims to calculate the MSY and other BRPs of $H$. nehereus and to provide the baseline stock information to the fishery administrator for the sustainable management of $H$. nehereus in the $\mathrm{BOB}$, Bangladesh.

\section{Materials and Methods}

\section{Data acquisition}

The study was conducted based on the catch and effort data collected from the Bay of Bengal area of Bangladesh (Fig. 1). The BOB is the northeastern part of the Indian Ocean, bordered by India on the west and northwest, by Bangladesh on the north, and Myanmar and India's Andaman and Nicobar Islands on the east. Bangladesh covers an area of 5.59\% while the total area of the BOB is 2172000 square km (Kumar et al., 2016). This 5.59\% area includes 24077 square $\mathrm{km}$ of shallow coastal and estuarine waters, 42007 square $\mathrm{km}$ of shallow shelf sea, 44383 square $\mathrm{km}$ of deep-sea, and 10644 square $\mathrm{km}$ of continental shelf (Chowdhury, 2014). For the H. Nehereus, data were collected from the estuarine, shallow coastal, and shelf-sea region where fishing activity is prominent. In this research, total of 17 years (2001-2017) catch and effort data were used from the Yearbook of Fisheries Statistics (YFS), produced by the Department of Fisheries (DoF), Bangladesh (Table 1). The total catch data was valued in tons ( $\mathrm{t}$ ) while fishing efforts was total number of fishing gears (trawl net, gill net and set bag net) per year (g/yr) and tons/gear/year $(\mathrm{t} / \mathrm{g} / \mathrm{yr})$ is the unit of catch per unit effort (CPUE). A single voyage for fishing in the BOB may take 3 to 4 weeks by the mechanize vessels while non-mechanize vessel voyages on a daily or an overnight basis. The voyaging duration may be influence by weather of the BOB (Barua et al., 2014; Karim et al., 2018). 


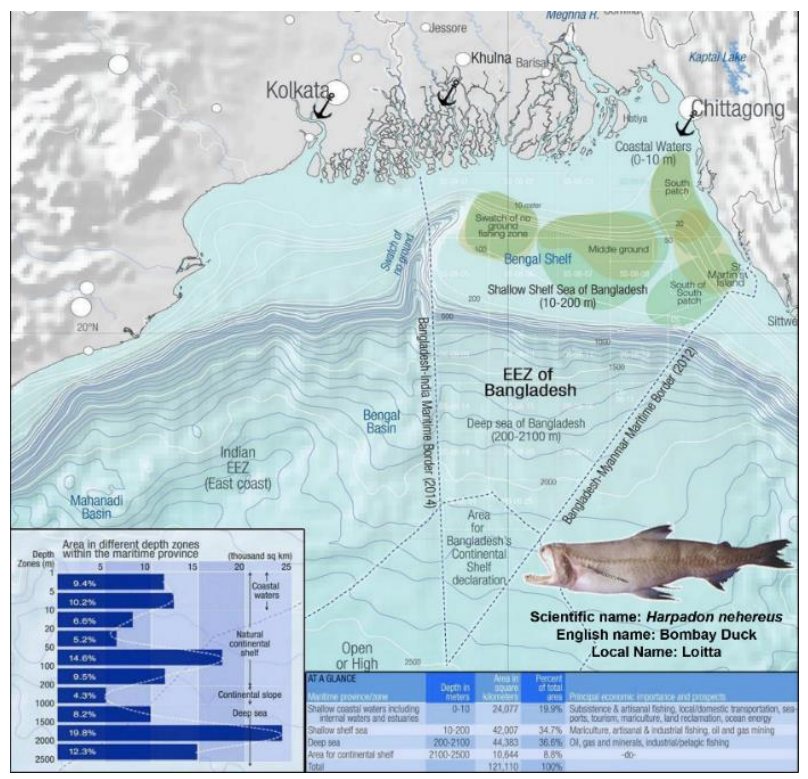

Figure 1. Map showing the information of the Bay of Bengal, Bangladesh (Chowdhury, 2014) and the figure of Bombay duck (Harpadon nehereus) species

Table 1. The seventeen years (2001-2017) time series fishery statistics of Harpadon nehereus from the Bay of Bengal, Bangladesh

\begin{tabular}{c|c|c|c}
\hline Year & $\begin{array}{c}\text { Catch } \\
(\mathbf{t})\end{array}$ & $\begin{array}{c}\text { Effort } \\
(\mathbf{g} / \mathbf{y r})\end{array}$ & $\begin{array}{c}\text { CPUE } \\
(\mathbf{t} / \mathbf{g} / \mathbf{y r})\end{array}$ \\
\hline 2001 & 37698 & 115274 & 0.33 \\
2002 & 39537 & 115274 & 0.34 \\
2003 & 41556 & 115274 & 0.36 \\
2004 & 41804 & 115274 & 0.36 \\
2005 & 43355 & 115354 & 0.38 \\
2006 & 39693 & 115362 & 0.34 \\
2007 & 40763 & 115369 & 0.35 \\
2008 & 64224 & 152595 & 0.42 \\
2009 & 64446 & 156102 & 0.41 \\
2010 & 66965 & 156110 & 0.43 \\
2011 & 69244 & 174708 & 0.40 \\
2012 & 79085 & 174579 & 0.45 \\
2013 & 56960 & 171239 & 0.33 \\
2014 & 59470 & 171914 & 0.35 \\
2015 & 64535 & 171914 & 0.38 \\
2016 & 76313 & 177477 & 0.43 \\
2017 & 82767 & 177492 & 0.47 \\
\hline Maximum & 82767 & 177492 & 0.47 \\
Menimum & 37698 & 115274 & 0.33 \\
Averege & 56966 & 146548 & 0.38 \\
\hline
\end{tabular}

$\mathrm{t}=$ tons, $\mathrm{g}=$ gears and $\mathrm{yr}=$ year

\section{CMSY and BSM model}

CMSY model was used to estimate the biomass, exploitation rate, MSY and related BRPs from catch data and resilience of Bombay duck fishery. Monte Carlo approach was applied to filter probable ranges for the maximum intrinsic growth rate $(r)$ and carrying 
capacity $(k)$. Viable $r$ - $k$ pairs were depicted in a triangular-shape in log-space if there is a positive growth trend. CMSY searched the most probable $r$ (maximum increase rate) of $H$. nehereus in the tip of the triangle. A Bayesian state-space implementation of Schaefer Model (BSM) used to calculate $r, k$ and MSY from CMSY (Eq. 1$)$. Another equation used to explain the reduced recruitment at severely depleted stock sizes where biomass falls below $1 / 4 k(E q .2)$.

$$
\begin{gathered}
B_{t+1}=B_{t}+r\left(1-\frac{B_{t}}{k}\right) B_{t}-C_{t} \\
B_{t+1}=B_{t}+4 \frac{B_{t}}{k} r\left(1-\frac{B_{t}}{k}\right) B_{t}-C_{t} \mid \frac{B_{t}}{k}<0.25
\end{gathered}
$$

where $\left(B_{t+1}\right)$ was exploited biomass in the year $t+1, B_{t}$ was current biomass, and $\mathrm{C}_{t}$ was catch in year $t$. The $H$. nehereus species resilience from FishBase were medium and the prior $r$-ranges was $0.2-0.8$ (Table 2). The prior $k$-range was attaining from three assumptions: (1) unexploited stock size $k$ is larger than the largest catch in the time series, (2) maximum sustainable catch ( $\left.F_{\mathrm{MSY}}\right)$ depends on productivity, $(3)$ maximum catch constitute larger fraction of $k$ in substantially depleted rather than lightly depleted stocks. By default, depending on assumed depletion level, possible biomass ranges (Table 3) provide prior estimates of relative biomass at the beginning and end of time series.

Table 2. Prior ranges for parameter $r$

\begin{tabular}{c|c}
\hline Prior $r$-range & Resilience \\
\hline $0.6-1.5$ & High \\
$0.2-0.8$ & Medium \\
$0.05-0.5$ & Low \\
$0.015-0.1$ & Very Low \\
\hline
\end{tabular}

Table 3. Prior biomass ranges relative to $k$

\begin{tabular}{c|c}
\hline $\boldsymbol{B} / \boldsymbol{k}$ & Prior biomass \\
\hline $0.5-0.9$ & High \\
$0.2-0.6$ & Medium \\
$0.01-0.4$ & Low \\
\hline
\end{tabular}

In the BSM, the uniform $r$-ranges from Table 2 were translated into prior densities with a central value. Also, abundance index was related to stock biomass by a catchability coefficient $q(E q .3)$ where $\mathrm{CPUE}_{t}$ was mean CPUE in year $t, B_{t}$ was biomass in year $t$ and $q$ was catchability coefficient for data-limited fishery.

$$
C P U E_{\mathrm{t}}=q B_{\mathrm{t}}
$$

The CMSY and BSM were implemented using an R-code (CMSY_0_7q.R), downloaded from http://oceanrep.geomar.de/33076/, and proposed by Froese et al. (2017). The JAGS software (Plummer, 2003) also applied for sampling the parameter's probability distributions with the Markov chain Monte Carlo method. To facilitate mixing of Gibbs samples, annual biomass was explicit relative to unexploited biomass with $\mathrm{P}_{t}=B_{t} / k$. CMSY and BSM estimated parameters of MSY $=r k / 4$, fishing mortality 
corresponding to MSY was $F_{\mathrm{MSY}}=0.5 r$, biomass corresponding to MSY was $B_{\mathrm{MSY}}=0.5 k$ (Schaefer, 1954; Ricker, 1975) and biomass below which recruitment may compromised as half of $B_{\mathrm{MSY}}$ (Haddon, 2011; Carruthers et al., 2014; Froese et al., 2015).

CMSY derived input values for prior distribution ranges were tabulated in Table 4. The prior initial relative biomass was $0.2-0.6$, prior intermediate relative biomass was 0.5-0.9 (in the year 2011), and prior final relative biomass was 0.4-0.8. The prior $r, k, q$ ranges were $0.2-0.8 / y r, 186000-4472000 \mathrm{t}$ and 7.05e-07-2.82e-06, respectively (Table 4).

Table 4. Input values of prior distributions of biomass, $r, k$, $q$ ranges

\begin{tabular}{c|c}
\hline Input parameters & Value ranges \\
\hline Prior initial relative biomass & $0.2-0.6$ \\
Prior intermediate relative biomass & $0.5-0.9$ (in year 2011) \\
Prior final relative biomass & $0.4-0.8$ \\
Prior range for $r$ & $0.2-0.8$ \\
Prior range of $q$ & $7.05 \mathrm{e}-07-2.82 \mathrm{e}-06$ \\
prior range for $k$ & $186000-4472000$ \\
\hline
\end{tabular}

\section{Results}

A gradual upgrading trend of catch and effort observed from the catch series data of Bombay duck in Table 1. Maximum effort (177492 g/yr) observed in the year 2017, where the maximum catch was 82767 t. Similarly, in the year 2001, minimum effort $(115274 \mathrm{~g} / \mathrm{yr})$ was recorded with a minimum catch (37698 t). The average catch of the 17 years was $56966 \mathrm{t}$ while the average effort recorded as $146548 \mathrm{~g} / \mathrm{yr}$ and average CPUE was $0.38 \mathrm{t} / \mathrm{g} / \mathrm{yr}$. The Gillnet and Set Bag Net $(\mathrm{SBN})$ were the predominantly used gears for fishing in the BOB, Bangladesh. Both the mechanized and non-mechanized fishing vessels voyaged for the fishing of $H$. nehereus fishery in BOB, Bangladesh.

The CMSY and BSM derived biological reference points for the Bombay duck fishery of BOB, Bangladesh are presented in Table 5. The maximum carrying capacity $(k)$ for $H$. nehereus estimated from BSM (652000 t) was larger than the CMSY estimate of 549000 t. For the BSM, a steno range of $k$ was observed at $95 \%$ confidence level compare with CMSY. The BSM derived catchability coefficient $(q)$ was $1.18 \mathrm{e}-06$, while the value of $q_{\text {low }}$ and $q_{\text {high }}$ was $8.86 \mathrm{e}-07$ and $1.56 \mathrm{e}-06$, respectively. The larger intrinsic rate of population size increase $(r)$ value $0.57 / \mathrm{yr}$ depicted from the CMSY model indicates the stock was able to increase its size above $50 \%$ of the actual population size per year. At the $95 \%$ confidence level, BSM produced a narrow range of $r$ compare to the CMSY model. At the $95 \%$ confidence level, a wide range of MSY values simulated from CMSY than BSM. The smallest MSY was estimated from BSM (60600 t), while CMSY produced MSY was $77600 \mathrm{t}$. Both models provided lower MSY values than the last year catch (82767 $\mathrm{t}$ in 2017), which indicates an over-exploitation status of Bombay duck fishery from BOB, Bangladesh.

Both CMSY and BSM model showed very closer biomass value, while larger $B_{\mathrm{MSY}}$ observed from the BSM model. BSM calculated biomass $(B=367076 \mathrm{t})$ was larger than the $B_{\text {MSY }}(326000 \mathrm{t})$ that indicate the stock was not depleted and in safe condition. The CMSY and BSM output also showed underfished biomass condition of H. Nehereus as the biomass ratio of $B / B_{\mathrm{MSY}}$ for both models depicted $>1.0$ value (Table 6 ). The BSM computed fishing mortality $(F=0.23 / \mathrm{yr})$ was greater than $F_{\mathrm{MSY}}(0.19)$ depicted overfishing happening. Higher fishing mortality observed from the BSM model 
$(F=0.23 / \mathrm{yr})$ than the CMSY model $(F=0.22 / \mathrm{yr})$, but the inverse scenario depicted for the

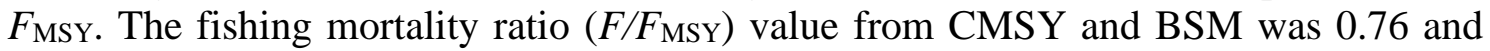
1.21 , respectively (Table 6). Based on the output from the Bayesian state-space Schaefer surplus production model, overfishing status was recognized for the Bombay duck fishery (Fig. 2). In summary, BSM derived $B / B_{\mathrm{MSY}}$ on $F / F_{\mathrm{MSY}}$ with time indicates healthy stock sizes of $H$. nehereus that are about to be depleted by overfishing in the BOB, Bangladesh (Fig. 2d).

Table 5. Estimated biological reference points (BRPs) for the Harpadon nehereus from the Bay of Bengal, Bangladesh, with the 95\% confidence intervals

\begin{tabular}{c|c|c|c}
\hline \multirow{2}{*}{$\begin{array}{c}\text { Model } \\
\text { Name }\end{array}$} & $\boldsymbol{3}(\mathbf{t})$ & $\boldsymbol{r}(/ \mathbf{y r})$ & $\mathbf{M S Y}(\mathbf{t})$ \\
\cline { 2 - 4 } & 549000 & 0.57 & 77600 \\
\multirow{2}{*}{ CMSY } & $(310000-974000)$ & $(0.41-0.79)$ & $(48000-125000)$ \\
& 652000 & 0.37 & 60600 \\
\multirow{2}{*}{ BSM } & $(467000-911000)$ & $(0.26-0.54)$ & $(50000-73500)$ \\
\hline
\end{tabular}

Table 6. Estimated $F, F_{M S Y}, F / F_{M S Y}, B, B_{M S Y}$ and $B / B_{M S Y}$ of the Harpadon nehereus from the Bay of Bengal, Bangladesh

\begin{tabular}{c|c|c|c|c|c|c}
\hline & $\boldsymbol{F}(/ \mathbf{y r})$ & $\boldsymbol{F}_{\text {MSY }}(/ \mathbf{y r})$ & $\boldsymbol{B}(\mathbf{t})$ & $\boldsymbol{B}_{\text {MSY }}(\mathbf{t})$ & $\boldsymbol{F} / \boldsymbol{F}_{\text {MSY }}$ & $\boldsymbol{B} / \boldsymbol{B}_{\text {MSY }}$ \\
\cline { 2 - 7 } CMSY & 0.22 & 0.285 & 387045 & 274500 & 0.76 & 1.41 \\
BSM & 0.23 & 0.19 & 367076 & 326000 & 1.21 & 1.13 \\
\hline
\end{tabular}
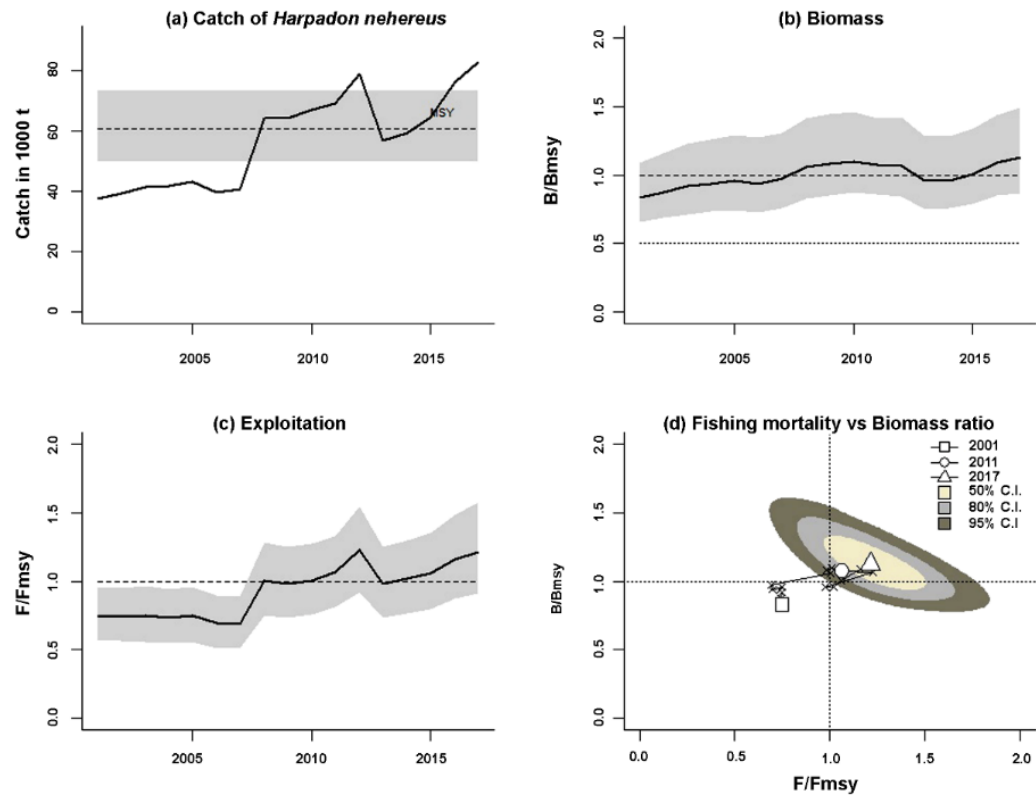

Figure 2. Exhibition of the information for management of Bombay duck (H. nehereus) fishery in the BOB, Bangladesh from BSM. (a) Catches and MSY (the grey color indicates $95 \%$ confidence intervals). (b) The ratio of the relative biomass $\left(B / B_{M S Y}\right)$ with uncertainty displayed with the grey area. $(c)$ Exploitation ratio $\left(F / F_{M S Y}\right)$, and $F_{M S Y}$ are adjusted for the recruitment below $0.5 B_{M S Y}(d)$ Stock size $\left(B / B_{M S Y}\right)$ and exploitation $\left(F / F_{M S Y}\right)$ relationship at $50 \%, 80 \%$ and 95\% confidence intervals (C.I.) with different shaded areas 


\section{Discussion}

Sustainable fisheries management mostly depends on outcomes of stock assessment study that provide valuable information for effective policy formulation for the fisheries resources. Scientists evaluate fishery stock status to propose the biological reference points (BRPs) estimated by different statistical methods. Fisheries scientist and managers consider $k, q, r$ and MSY values for the sustainable management of any fisheries (Hilborn and Walters, 1992; Froese et al., 2017; Baset et al., 2017; Mohsin et al., 2018; Ji et al., 2019; Khatun et al., 2019). The recent developed CMSY and BSM models were applied to estimate the BRPs for $H$. nehereus from the BOB, Bangladesh in this study.

For the CMSY and BSM, the $k$ and $r$ were the required prior information which can be attained from the Fishbase resilience data (Martell and Froese, 2013; Froese and Pauly, 2015). As per ICES (2015) simulation tests, CMSY is not well suited for the very low resilience or very lightly harvested fishery. The resilience value of Bombay duck fishery was medium (prior $r=0.2-0.8$ ) from the Bay of Bengal. So far, CMSY may be the best alternative approach for this data poor stock from BOB, Bangladesh (Froese et al., 2017). Catch, effort, and CPUE are major indicators to evaluate the fishery stock status. Catchability coefficient $(q)$ denotes the ratio between fishing mortality and fishing efforts, so-called the efficiency of fishing gears. The $q$ was also important where catch and effort data used as a critical component for the study of the fish population dynamics. The $q$ may be influenced by the variability of the temporal and spatial distribution of the fish stock and fishing fleets (Hoggarth et al., 2006).

FiSAT is a computer software package able to calculate $r$ using the von Bertalanffy growth parameters (Sullivan, 1991; Gayanilo et al., 2005). Sullivan (1991) suggested a prognostic equation was: $r=0.947+1.189 k-0.095 \ln \left(\mathrm{W}_{\infty}\right)$. These equations recommended that the intrinsic growth rate was proportionate with the von Bertalanffy growth rate while inverse with body size. Furthermore, the prior value of $r$ was relayed with natural mortality $(M)$ and calculated as $r=2 M$ (Froese et al., 2017). Also, Pauly (1980) proposed an empirical formula for $M$ estimation that was further reviewed by the Kenchington (2014) for data-limited fisheries. Compare with other models, the $r$-value from CMSY ( $r=0.57$ ) indicated the medium growth rate for the Bombay duck fishery in the BOB, Bangladesh, and the fishery was capable enough of adding above $50 \%$ more biomass in the existing population per year. It was mentioned that $r$ of 0.1 implies that a population will increase by $10 \%$ in a time interval (McAllister et al., 2001; Hoggarth et al., 2006). There is a high correlation between the population growth rate $r$ and the population size $k$, either large $r$ or large $k$ can produce large catch, this a difficult question in fish population dynamics. Additionally, increasing fishing intensity may increase catch that may decrease the population size.

MSY was the foundation of most BRPs, so-called technical reference point (TRP), that exhibited an explicit assumption about a fishery status (ICES, 2015). If the observed catch was lower than the estimated MSY, it means the flourishing fishery stock, and the higher observed catch than estimated MSY indicates the overexploited status of fishery stock (Gabriel and Mace, 1999; Hoggarth et al., 2006; Rosenberg et al., 2014). The estimated MSY from CMSY and BSM model was $77600 \mathrm{t}$ and $60600 \mathrm{t}$ respectively for the $H$. nehereus fishery from BOB, Bangladesh. Though both models produced smaller MSY value, BSM made the lowest MSY value compare with the last year catch $(82767 \mathrm{t}$ in 2017), indicated the Bombay duck fishery overexploited from the BOB, Bangladesh. In the literature several authors studied the length-weight relationship of Bombay duck 
fishery from the BOB, Bangladesh and found the over-exploited status (Mustafa et al., 1994; Islam, 1995; Mustafa et al., 1998; Sarker et al., 2017).

Both CMSY and BSM model produced $B / B_{\text {MSY }}$ ratio $>1.0$ denotes the under-fished condition and safe biomass of the Bombay duck fishery. The demarcation of $B / B_{\mathrm{MSY}}$ ratio varies by governing body (such as UN, FAO signifies under-fished when the value under 0.8, while the USA considers it under 0.5) (Hoggarth et al., 2006). On the other hand, $F / F_{\text {MSY }}$ ratio $<1$ was produced by CMSY, while BSM produced $F / F_{\text {MSY }}$ ratio was $>1.0$. From the BSM output results and figure, it is clarified that the Bombay duck fishery in the BOB, Bangladesh was in overfishing condition, but the biomass was in under-fished status, which depicted that the fishery remains sustainable. However, this healthy stock sizes are about to be depleted by overfishing and become unsustainable (Sumaila and Tai, 2020). Overfishing may lose the balanced with millions of fish species and other marine animals in the marine water and overfishing fishing for particular specie may lead it to be extinct. Contineus overfishing practice may distort the food chain and truncating the food web that are threats for the ocean health and will ripple up and down to all the living organisms (Chuenpagdee et al., 2003; Halpern et al., 2015; Gattuso et al., 2018; Sumaila and Tai, 2020). Therefore, management strategies should be strict to control the overfishing status for this fishery to ensure the sustainability of marine fisheries of Bangladesh. This research recommends that the annual catch of $H$. nehereus from the BOB, Bangladesh should not exceed the MSY limit estimated by the BSM model (60600 t) because the smallest value of the MSY should be recommended for the management target of any fishery (Martell and Froese, 2013). Also, illegal fishing and non-license fishing vessel operation should be controlled strictly to ensure the sustainable harvest of this fishery from the Bay of Bengal, Bangladesh.

However, more research on population biology and dynamics are recommended to restrict the overexploitation of this fishery. Because it is much controversial to imply catch data for stock estimation (Pauly et al., 2013), but for the unassessed fishery, most of the method depends on it. The outcomes of this research can be helpful to study growth and other biological parameters to have accurate knowledge of the population dynamics of this fish species.

\section{Conclusion}

Harpadon nehereus is one of the essential fisheries in Bangladesh. In the Bay of Bengal, the catch of this fishery was gradually increased up to $82767 \mathrm{t}$ from 2001 to 2017 with the continues lifting of fishing effort. Fishery reference points derived from the CMSY and BSM model indicated that the H. nehereus biomass in the BOB was still in sustainable condition, but the overfishing scenario may lead the fishery unsustainable. To ensure the sustainability of this fishery, the results recommend that total allowable catch (TAC) should not exceed the $60600 \mathrm{t}$ from the BOB, Bangladesh. To verifiy this prediction, further studies could be done to assess the stock status accurately along with the length-weight data. More exclusive research on biology and ecology of this fishery is recommended to establish a complete management plan. Also government should take immediate measures to reduce the fishing efforts. Fishery managers and policymakers may use this research information to ensure sustainable management of the Bay of Bengal fishery as well as other data-limited fishery of Bangladesh. 
Acknowledgments. The authors would like to express gratefulness to the Chinese Scholarship Council (CSC) and SOA (State Oceanic Administration) and Central University Basic Research Fund (NO: 201562030) of Ocean University of China for sponsorship of this research. The authors are also grateful to Sylhet Agricultural University authority for their valuable care and supports.

\section{REFERENCES}

[1] Amin, S. M. N. (2001): Studies on Age and Growth, VPA Analysis and Relative Condition Factor of Harpodon nehereus (Ham-Buch) from the Neritic Water of Bangladesh. - Online Journal of Biological Science 1: 192-194. https://doi.org/10.3923/jbs.2001.192.194.

[2] Barua, S., Karim, E., Humayun, N. M. (2014): Present Status and Species Composition of Commercially Important Fin-fish in Landed Trawl Catch from Bangladesh Marine Waters. - International Journal of Pure and Applied Zoology 2(2): 150-159.

[3] Baset, A., Liu, Q., Hanif, M. T., Liao, B., Mahmood, A. M., Mohsin, M. (2017): Estimation of Maximum Sustainable Yield Using Production Modeling: A Stock Appraisal of Indian Oil Sardine (Sardinella longiceps) from Pakistani Waters. - Pakistan Journal of Zoology 49(2): 485-492. https://doi.org/10.17582/journal.pjz/2017.49.2.485.492.

[4] Carruthers, T. R., Punt, A. E., Walters, C. J., MacCall, A., McAllister, M. K., Dick, E. J., Cope, J. (2014): Evaluating methods for setting catch limits in data-limited fisheries. Fisheries Research 153: 48-68. https://doi.org/10.1016/j.fishres.2013.12.014.

[5] Chowdhury, S. R. (2014): Maritime Province of Bangladesh (map). - University of Chittagong, Bangladesh. http://imsfcu.ac.bd/imsf-publishes-countrys-first-maritime-map/.

[6] Chuenpagdee, R., Morgan, L. E., Maxwell, S. M., Norse, E. A., Pauly, D. (2003): Shifting gears: assessing collateral impacts of fishing methods in US waters. - Front. Ecol.Environ. 1: 517-524. https://doi:10.1890/1540-9295(2003)001[0517:SGACIO]2.0.CO;2.

[7] Dick, E. J., MacCall, A. D. (2011): Depletion-Based Stock Reduction Analysis: A catchbased method for determining sustainable yields for data-poor fishstocks. - Fisheries Research 110(2): 331-341. https://doi.org/10.1016/j.fishres.2011.05.007.

[8] DoF. (2018): Yearbook of Fisheries Statistics of Bangladesh, 2017-2018. - Director General Department of Fisheries, Bangladesh, Dhaka.

[9] Fernandes, J. A., Kay, S., Hossain, M. A. R., Ahmed, M., Cheung, W. W. L., Lazar, A. N., Barange, M. (2015): Projecting marine fish production and catch potential in Bangladesh in the 21 st century under long-term environmental change and management scenarios. ICES Journal of Marine Science 73(5): 1357-1369. https://doi.org/doi:10.1093/icesjms/fsv217.

[10] Froese, R., Pauly, D. (2015): Fishbase. - Version (02/2015) world wide web electronic publication. Retrieved from http://www.fishbase.org.

[11] Froese, R., Demirel, N., Coro, G., Kleisner, K. M., Winker, H. (2017): Estimating fisheries reference points from catch and resilience. - Fish and Fisheries 18(3): 506-526. https://doi.org/10.1111/faf.12190.

[12] Gabriel, W. L., Mace, P. M. (1999): A review of biological reference points in the context of the precautionary approach. - In: Restrepo, V. R. (ed.) Proceedings of the $5^{\text {th }}$ National NMFS Stock Assessment Workshop: Providing Scientific Advice to Implement the Precautionary Approach under the Magnuson-Stevens Fishery Conservation and Management Act. NOAA Tech. Memo. NMFS-F/SPO- 40. pp. 34-45.

[13] Gattuso, J. P., Magnan, A. K., Bopp, L., Cheung, W. W., Duarte, C. M., Hinkel, J., Mcleod, E., Micheli, F., Oschlies, A., Williamson, P., Bille, R. (2018): Ocean solutions to address climate change and its effects on marine ecosystems. - Frontiers in Marine Science 5: 337. https://doi:10.3389/fmars.2018.00337.

[14] Gayanilo, F. C., Sparre, P., Pauly, D. (2005): FAO-ICLARM stock assessment tools II (FiSAT II). User's guide No. 8. - Food and Agriculture Organization, Rome, Italy. 
[15] Haddon, M. (2011): Modeling and Quantitative Methods in Fisheries. $2^{\text {nd }}$ ed. - Chapman and Hall/CRC, Boca Ratno, FL.

[16] Halpern, B. S., Frazier, M., Potapenko, J., Casey, K. S., Koenig, K., Longo, C. (2015): Spatial and temporal changes in cumulative human impacts on the world's ocean. - Nat Commun 6: 1-7. https://doi:10.1038/ncomms8615.

[17] Hilborn, R., Walters, C. J. (1992): Quantitative fisheries stock assessment: choice, dynamics and uncertainty. - Reviews in Fish Biology and Fisheries 2(2): 177-178.

[18] Hoggarth, D. D., Abeyasekera, S., Arthur, R. I., Beddington, J. R., Burn, R. W., Halls, A. S., Kirkwood, G. P., McAllister, M., Medley, P., Mees, C. C., Parkes, G. B., Pilling, G. M., Wakeford, R. C., Welcomme, R. L. (2006): Stock Assessment for Fishery Management-A Framework Guide to the Stock Assessment Tools of the Fisheries Management Science Programme. - FAO Fisheries Technical Paper 487. FAO, Rome.

[19] Hossain, M. A., Thompson, B. S., Chowdhury, G. W., Mohsanin, S., Fahad, Z. H., Koldewey, H. J., Islam, M. A. (2015): Saw-fish exploitation and status in Bangladesh. Aquatic Conservation: Marine and Freshwater Ecosystem 25: 781-899. https://doi.org/10.1002/aqc.2466.

[20] ICES. (2015): Report of the fifth workshop on the development of quantitative assessment methodologies based on life-history traits. - In: Exploitation Characteristics and Other Relevant Parameters for Data-limited Stocks (WKLIFE V), 5-9 October 2015, Lisbon, Portugal. ICES CM 2015/ACOM 56: 157.

[21] Islam, S. S. (1995): Population dynamics of some fishes and shrimp of Karnafully river estuary based on length-frequency data. - Unpublished MS Thesis, Department of Zoology, University of Chittagong, Bangladesh.

[22] Ji, Y., Liu, Q., Liao, B., Zhang, Q., Han, Y. N. (2019): Estimating biological reference points for Large head hairtail (Trichiurus lepturus) fishery in theYellow Sea and Bohai Sea. - Acta Oceanologica Sinica 38(10): 1-7. https://doi.org/10.1007/s13131-019-1343-4.

[23] Karim, E., Liu, Q., Khatun, M. H., Rahman, M. F., Memon, A. M., Hoq, M. E., Mahmud, Y. (2018): Estimation of the marine Pomfret fishery status of the Bay of Bengal, Bangladesh: Sustainability retained. - Indian Journal of Geo Marine Science 47(3): 686693. http://nopr.niscair.res.in/handle/123456789/44112.

[24] Kenchington, T. J. (2014): Natural mortality estimators for information-limited fisheries. Fish and Fisheries 15: 533-562. https://doi.org/10.1111/faf.12027.

[25] Khatun, M. H., Lupa, S. T., Rahman, M. F., Barman, P. P., Liu, Q. (2019): Evaluation of Labeo calbasu Fishery Status Using Surplus Production Models in Kaptai Reservoir, Bangladesh. - Applied Ecology and Environmental Research 17(2): 2519-2532. https://doi.org/http://dx.doi.org/10.15666/aeer/1702_25192532.

[26] Kirkwood, G. P., Aukland, R., Zara, S. J. (2003): Catch Effort Data Analysis (CEDA) Version 3.0. - MRAG Ltd, London, UK.

[27] Kumar, U., Parvez, M. S., Das, J., Nizamuddowla, C. M., Tarafdar, S. R. (2016): Capture Fisheries Scenario of the Bay of Bengal, Bangladesh in last two decades through Industrial Freezer Trawler. - Res. Agric. Livest. Fish. 3(1): 217-226. https://10.3329/ralf.v3i1.27880.

[28] MacCall, A. D. (2009): Depletion-corrected average catch: a simple formula for estimating sustainable yields in data-poor situations. - ICES Journal of marine Science 66(10): 22672271. https://doi.org/10.1093/icesjms/fsp209.

[29] Martell, S., Froese, R. (2013): A simple method for estimating MSY from catch and resilience. - Fish and Fisheries 14(4): 505-514. https://doi.org/10.1111/j.14672979.2012.00485.x.

[30] McAllister, M. K., Pikitch, E. K., Babcock, E. A. (2001): Using demographic methods to construct Bayesian priors for the intrinsic rate of increase in the Schaefer model and implications for stock rebuilding. - Canadian Journal of Fisheries and Aquatic Sciences 58(9): 1871-1890. https://doi.org/10.1139/f01-114.

[31] Mohsin, M., Mu, Y., Memon, A. M., Kalhoro, M. T., Shah, S. B. H. (2017): Fishery stock assessment of Kiddi shrimp (Parapenaeopsis stylifera) in the Northern Arabian Sea Coast 
of Pakistan by using surplus production models. - Chinese journal of oceanology and limnology 35(4): 936-946. http://dx.doi.org/10.1007/s00343-017-6096-3.

[32] Mohsin, M., Mu, Y., Shafqat, M. M., Memon, A. M. (2018): MSY Estimates of Cephalopod Fishery and Its Bio-economic Implications in Pakistani Marine Waters. International Journal of Marine Science 8(18): 151-159. https://doi.org/10.5376/ijms.2018.08.0018.

[33] Mustafa, M. G., Azadi, M. A., Islam, M. S. (1994): ELEFAN based population dynamics of Bombay duck Harpadon nehereus Hamilton-Buchman from the Kumira estuary. $-9^{\text {th }}$ National Zoological Conference 26-28.

[34] Mustafa, M. G., Zafar, M., Matin, A. K. M. A., Amin, S. M. N. (1998): Population dynamics of Harpodon nehereus (Ham. -Buch.) from the Kutubdia channel of Bangladesh. - Bangladesh Journal of Fisheries Research 2: 83-90.

[35] Panhwar, S. K., Liu, Q., Khan, F., Waryani, B. (2012): Maximum sustainable yield Estimates of spiny lobster fishery in Pakistan using non-equilibrium CEDA package. Russian Journal of Marine Biology 38(6): 448-453. https://doi.org/10.1134/S1063074012060077.

[36] Pauly, D. (1980): On the interrelationships between natural mortality, growth parameters, and mean environmental temperature in 175 fish stocks. - ICES Journal of Marine Science 39(2): 175-192. https://doi.org/10.1093/icesjms/39.2.175.

[37] Pauly, D., Hilborn, R., Branch, T. A. (2013): Fisheries: does catch reflect abundance? Nature 494(7437): 303. https://doi.org/10.1038/494303a.

[38] Plummer, M. (2003): JAGS: a program for analysis of Bayesian graphical models using Gibbs sampling. - In: Hornik, K., Leisch, F., Zeileis, A. (eds.) International Proceedings of the $3^{\text {rd }}$ International Workshop on Distributed Statistical Computing (DSC 2003) March 20-22, Vienna, 2003. Vienna Technical University, Vienna pp. 20-22.

[39] Prager, M. (2005): A Stock-Production model incorporating covariates (version 5) and auxiliary programs, (CCFHR (NOAA). - Miami Laboratory Document MIA-92/93-55, Beaufort Laboratory Document BL-2004-01.

[40] Rosenberg, A. A., Fogarty, M. J., Cooper, A. B., Dickey-Collas, M., Fulton, E. A., Gutiérrez, N. L., Hyde, K. J., Kleisner, K. M., Kristiansen, T., Longo, C., Minte-Vera, C. V. (2014): Developing new approaches to global stock status assessment and fishery production potential of the seas. - FAO Fisheries and Aquaculture Circular No. 1086 FIRF/C1086, FAO, Rome.

[41] Sarker, M. N., Humayun, M., Rahman, M. A., Uddin, M. S. (2017): Population dynamics of Bombay duck Harpodon nehereus (Hamilton, 1822) of the Bay of Bengal along Bangladesh coast. - Bangladesh Journal of Zoology 45: 101-110. https://doi.org/http://dx.doi.org/10.3329/bjz.v45i2.35705.

[42] Siddeek, M. S. M., Sainte-Marie, B., Boitillier, J., Bishop, G. (2004): Comparison of reference point estimated using a side-based method for two high latitude crab species in the United States and Canada. - Canadian Journal of Fisheries and Aquatic Sciences 61(8): 1404-1430. https://doi.org/10.1139/f04-137.

[43] Sullivan, K. J. (1991): The estimation of parameters of the multi species production model. - ICES Journal of Marine Science 193: 185-193.

[44] Sumaila, U. R., Tai, T. C. (2020): End Overfishing and Increase the Resilience of the Ocean to Climate Change. - Frontiers in Marine Science 7: 523. https://doi:10.3389/fmars.2020.00523.

[45] Wang, Y., Liu, Q. (2013): Application of CEDA and ASPIC computer packages to the hairtail (Trichiurus japonicus) fishery in the East China Sea. - Chinese Journal of Oceanology and Limnology 31(1): 92-96. https://doi.org/10.1007/s00343-013-2073-7.

[46] Zhang, K., Chen, Z. (2015): Using Bayesian state-space modelling to assess Trichiurus japonicus stock in the East China Sea. - Journal of Fishery Sciences of China 22(5): 10151026. (in Chinese). 
[47] Zhang, K., Zhang, J., Xu, Y., Sun, M., Chen, Z., Yuan, M. (2018): Application of a catchbased method for stock assessment of three important fisheries in the East China Sea. Acta Oceanologica Sinica 37(2): 102-109. https://doi.org/10.1007/s13131-018-1173-9. 